\title{
Beneficial effects of Camelina sativa oil on behavioural (memory, anxiety, depression and social-related) manifestations and oxidative stress parameters in a mice model of irritable bowel syndrome
}

\author{
ROXANA COJOCARIU1, IOANA BALMUS ${ }^{1,2}$, RADU LEFTER $^{3}$, LUMINITA HRITCU ${ }^{4}$, \\ DANA ABABEI ${ }^{5}$, ALIN CIOBICA ${ }^{1,3,5}$, SIMONA COPACI ${ }^{6}$, LUCIAN COPOLOVICI $^{7}$, DANA \\ COPOLOVICI ${ }^{7 *}$, STEFANA JURCOANE ${ }^{6,8}$ \\ ${ }^{1}$ Faculty of Biology, Department of Research, Alexandru Ioan Cuza University, B-dul Carol I, no 11, Iasi, Romania \\ ${ }^{2}$ Department of Interdisciplinary Research in Science, Alexandru Ioan Cuza University of Iasi, Carol I Avenue, no. 11, Iasi \\ 700506, Romania \\ ${ }^{3}$ Center of Biomedical Research, Romanian Academy, Iasi, B-dul Carol I, no 8, Romania \\ ${ }^{4}$ Faculty of Veterinary Medicine, University of Agricultural Sciencies and Veterinary Medicine "Ion Ionescu de la \\ Brad" of Iasi, $3^{\text {rd }}$ Mihail Sadoveanu Alley, Iasi 700490, Romania \\ 5"Grigore T. Popa" University of Medicine and Pharmacy, $16^{\text {th }}$ Universitatii Street, 700115 Iasi, Romania \\ ${ }^{6}$ Faculty of Biotechnology, University of Agronomic Sciences and Veterinary Medicine Bucharest 59, Bd. Marasti, \\ 011464 Bucharest, Romania \\ ${ }^{7}$ Faculty of Food Engineering, Tourism and Environmental Protection; and Institute for Research, Development \\ and Innovation in Technical and Natural Sciences, "Aurel Vlaicu" University of Arad, Elena Dragoi St. nr. 2, \\ 310330, Arad, Romania \\ ${ }^{8}$ Academy of Romanian Scientists, Splaiul Independentei nr. 54, sector 5, 050094 Bucuresti, Romania
}

\begin{abstract}
Irritable bowel syndrome (IBS) is a common chronic functional gastrointestinal impairment, which includes also a variety of psychological and psychiatric comorbidities. The oxidative stress was earlier reported as presenting an important part of the IBS complex pathophysiology. In the present study, we determined the fatty acids profile and thereafter the effects of Camelina sativa Madalina variety cold pressed oil in a zymosan-induced model of IBS. We are showing here some facilitatory effects of the Camelina sativa oil in this context, both on the behavioral and oxidative stress-related actions. Thus, all these results are suggesting some beneficial effects for the present Camelina sativa oil used in this study on behavioural (memory, anxiety, depression and social-related) manifestations and oxidative stress parameters in a zymosan-induced mice model of irritable bowel syndrome. This could be relevant for the connections between the physiological manifestations in IBS and its depressive-like or anxiolytic-like manifestations. In conclusion, Camelina sativa oil exerted facilitatory effects on both the behavioral (short memory, as tested in the Y maze task, anxiety-tested in the elevated plsu maze, depression, as observed in the forced swimming test and social-dominance test) and oxidative stress-related actions (mainly manifested through a general increase of the two main antioxidant enzymes determined here: superoxide dismutase and glutathione peroxidase, as well as a decrease in the lipid peroxidation marker malondialdehyde).
\end{abstract}

Keywords Camelina sativa oil, behavioural, memory, anxiety, depression, oxidative stress, irritable bowel syndrome.

To cite this article: COJOCARIU R, BALMUS I, LEFTER R, HRITCU L, ABABEI D, CIOBICA A, COPACI S, COPOLOVICI L, COPOLOVICI D, JURCOANE S. Beneficial effects of Camelina sativa oil on behavioural (memory, anxiety, depression and social-related) manifestations and oxidative stress parameters in a mice model of irritable bowel syndrome. Rom Biotechnol Lett. 2020; 25(3): 1532-1540. DOI: 10.25083/rbl/25.3/1532.1540 


\section{Introduction}

Irritable bowel syndrome (IBS) is a common chronic functional gastrointestinal impairment. IBS symptomatology includes a high degree of variability mainly due to individual differences. Generally characterized by abdominal bloating and bowel habit changes such as diarrhoea, constipation, abdominal bloating, incomplete defecation accompanied by pain or burning sensation, IBS diagnosis is also based on other symptoms derived or caused by the primary symptoms such as flatulence and gas emission, mucous stools. Despite the burden and sometimes the severity of these symptoms, IBS is characterized by the absence of any structural damage which makes this disorder hard to diagnose through radiological or endoscopic changes, and laboratory tests are deficient (LONGSTRETH \& al, 2006 [1]).

In 1892, Osler invented the term mucosal colitis when describing a mucosal and abdominal disorder with a high incidence in psychopathology patients. Although the psychopathology of IBS is not yet fully known, the hypothesis of the involvement of the gut-brain axis is accepted, however deficiency or impairment of brain-gut axis's at any level could complement the picture of a condition based on both the gastrointestinal tract and the central nervous system (MAYER, 2011 [2]). In this way, IBS was recently described, by ROME IV, as a complex disorder involving gastrointestinal symptomatology as well as neurological impairments in the enteric nervous system, hypothalamic-pituitary-adrenal (HPA) axis, and also central nervous system (COJOCARIU \& al, 2019 [3]). Previous research showed that important stress-coping mechanisms are implicated in IBS as well as several cognitive changes regarding affective spectrum behaviours (depressive and anxious behaviours) and social deficiencies (LEFTER \& al, 2018 [4]).

Since any impairment in the body caused or could be caused by a signalling misuse, and oxidative stress occurs on the biggest signalling pathway (through reactive species transport and metabolism) (COJOCARIU \& al, 2019 [3], LEFTER \& al, 2018 [4]), any imbalance in the normal redox state leads to toxicity by producing free radicals and peroxides with deleterious effect on proteins, lipids and cellular DNA. In this way, the vicious circle between the production of reactive oxygen species and the inability of the body to detoxify the biological system of these species reverberate in the deficiency to repair the resulting damage. It is a fundamentally known pattern that the nervous system is susceptible to lesions caused by oxidative stress due to lipid structures and low antioxidant content.

However, oxidative stress was described as causes, components or effects of many disorders including gastrointestinal impairments (ACHITEI \& al, 2013 [5], ILIE \& al, 2020 [6]). In this way, previous research reported the implication of oxidative stress in several IBS animal models and also in human IBS patients (COJOCARIU \& al, 2019 [3], LEFTER \& al, 2018 [4], CHAUDHARI \& al, 2014 [7], BĂTRÎNA \& al, 2020 [8]).

Therapeutic approaches involving treatments with effect on symptomatology were used, given the fact that there is no specific IBS cure so far (BASNAYAKE, 2018 [9]). In this regard, besides the pharmaceutical compounds most of which are designed for other targets, the tendency is to resort to cognitive behavioural therapy, multicomponent psychological therapy, dynamic psychotherapy, hypnotherapy and herbal therapy for relieving the symptoms (FORD \& al, 2014 [10]).

The Camelina oil obtained from plants harvested in Romania was previously obtained, analysed (DOMIL \& PÎRVULESCU, 2015 [11], POPA \& al, 2019 [12]) and it was recently demonstrated to exhibit potential in different applications in pharmaceutical and cosmetic industry due to the fact that it can stimulate the keratinocytes differentiation and turn-over, collagen synthesis, and the fibroblasts cellular division (CRACIUN \& al, 2019 [13]). Thus, in this study, we determined the fatty acids profile and the effects of Camelina sativa Madalina variety cold pressed oil in a zymosan- induced model of IBS. Zymosan is a structural component, a known polysaccharide prepared from the cell wall of Saccharomyces cerevisiae (PILLEMER \& ECKER, 1941 [14]), which served as a model for recognition of microbes by the innate immune system in one hand, and induces inflammatory signals in macrophages through Toll-like receptors TLR2 and TLR6, on the other hand (UNDERHILL, 2003 [15]). Moreover, zymosan interacts with dectin-1 receptors on macrophages to stimulate the release of pro-inflammatory mediators (TAGHAVI \& al, 2018 [16]).

Given the fact that our group previously demonstrated the antioxidant capacity and neuropharmacological active profile of Chrysanthellum americanum extracts in a rat model of IBS (COJOCARIU \& al, 2019 [3]) and described the alleviating potential on behavioural and oxidative stress in a complex nice model of IBS (data not published yet), our aim was to reveal Camelina sativa Madalina variety cold pressed oil effect in a zymosan- induced model of IBS on both behavioral and oxidative stress-related actions. In this way, we determined fatty acid profile of the oil by gas chromatography, then we evaluated short-term memory following behavioral testing using Y Maze test (YM), the anxious behavior using Elevated Plus Maze test (EPM) and the antidepressant effect after using Forced Swimming Test (FST). We determined the oxidative status evaluating superoxide dismutase (SOD) and glutathione peroxidase (GPx) enzymes activity and malondialdehyde (MDA) levels. Moreover, we were interested in revealing correlations between the behavioural parameters we determined and the levels of the oxidative stress markers.

\section{Materials and Methods}

\section{Determination of fatty acids profile}

Seeds of Camelina sativa, Madalina variety were obtained from plants cultivated without using fertilisers at Moara Domnească Teaching Farm of University of Agronomic Sciences and Veterinary Medicine Bucharest, in 2017. The pressed cold oil was obtained and analysed by using a modified earlier published method (COPOLOVICI \& al, 2017 [17], CSAKVARI \& al, 2019 [18], RABA \& al, 2018 [19]). The methyl esters of fatty acids contained in the samples were obtained and chromatographed as follows: $0.3 \mathrm{~mL}$ of oil samples together with $0.6 \mathrm{ml}$ of methanol/ toluene/sulphuric acid (88/10/2, v/v/v) solution mixture were pipetted into Eppendorf tubes, vigorously vortexed and then kept at $80^{\circ} \mathrm{C}$ for one hour in a block heater (Stuart 
block heater, Staffordshire, UK). The resulting methyl esters were extracted twice with $0.5 \mathrm{ml}$ of n-heptane and analysed by gas chromatography coupled with mass spectrometry (GC-MS 2010 Plus-TQ8040 equipment, Shimadzu, Kyoto, Japan). An Optima DB 5 chromatographic capillary column (30 m length; $0.25 \mathrm{~mm}$ i.d.; $0.25 \mu \mathrm{m}$ film thickness, MACHEREY-NAGEL GmbH \& Co. KG, Düren, Germany) and helium as the carrier gas at a flow rate of $0.93 \mathrm{~L} \mathrm{~min}^{-1}$ have been used. The injector temperature and MS source were maintained at a temperature of $250^{\circ} \mathrm{C}$ and $200^{\circ} \mathrm{C}$, respectively. Identification of fatty acid methyl esters has been performed based on their mass spectra using commercial mass spectra libraries: NIST 14 library and Willy 09 library, and real standards. All the chemical reagents were of chromatographic grade and were bought from Sigma-Aldrich, Germany. All measurements were performed in triplicates.

\section{Animals and Treatments}

Male Swiss mice at an initial body mass of 30-40 $\mathrm{g}$ were used according to Helsinki Declaration and in accordance with the legislation of Romania and the European Union on the use of animals in biomedical experiments. The animals $(n=24)$ were randomly assigned to 4 groups ( $n=6$ per group): (1) control group; (2) IBS group (with zymosan administration); (3) IBS - Camelina oil group which received both zymosan and Camelina oil treatments; (4) Camelina oil group which received Camelina cold pressed oil. Zymosan (Sigma) was administered for 3 consecutive days under permanent observation. Camelina sativa oil was administered in a dose of $0,6 \mathrm{ml}$, for 5 consecutive days. In the case of combined administration group, the Camelina oil was administered 5 day after the end of zymosan treatment. Saline solution $(\mathrm{NaCl} 0.9 \%)$ was administered to control group at a volume of $2 \mathrm{ml} / \mathrm{kg}$ body weight, equivalent to other treatments volumes.

\section{Behavioral testing}

The animals were subjected to behavioral tests in the following order: Y maze test, Elevated-plus maze, Forced swim test, Social dominance test and were performed from the following day after all treatments were completed.

\subsection{Y Maze Test}

$\mathrm{Y}$ maze test is generally used for short-term memory assessment by evaluating the successive and alternating exploration behaviour of the three arms of the Y-shaped apparatus. The maze used in the present study consisted of three arms and an equilateral triangular central area.

\subsection{Elevated plus maze}

Elevated maze test is a common behavioural test used to assess anxiety-like behaviours. The test is based on the conflict that arises between the mouse's tendency to explore the labyrinth and the tendency to avoid a new stimulus that can be adversely. For assessing anxiety, the time spent in the open arms, head-dipping behaviour, time of grooming and periods of freezing were recorded, in a mice dimension specific maze.

\subsection{Forced swimming test}

The forced swim test is used to observe the depressive behaviour and behavioural despair. A transparent glass water-safe-filled container was used. The protocol consists in placing individuals in a transparent cylinder $(30 \mathrm{~cm}$ in diameter, height $59 \mathrm{~cm})$ filled with water $\left(25 \mathrm{~cm}, 26^{\circ} \mathrm{C}\right)$, being forced to swim. The animals were exposed to the experimental conditions for 15 minutes. In the following say, the animals were re-exposed in a shorter period, during which the following behavioral parameters are recorded: immobility (floating), struggle (vigorous upward movements) and swimming.

\subsection{Social dominance test}

The social dominance test is useful for identifying deficits in social interactions and to assess animal aggressivity. In a transparent plexiglas tube measuring $45 \mathrm{~cm}$ in length and $4 \mathrm{~cm}$ in (inside) diameter, the subjects are observed regarding the tendency to cross the tube to the other end. The animals interact in the middle and the more dominant animal will show greater aggression and force its opponent out of the tube.

\section{Biochemical determinations}

4.1. Superoxide dismutase (SOD) activity determination

To determine the enzymatic activity of SOD, the "19160 SOD determination kit" determination kit (SigmaAldrich, USA) was used. This kit uses an indirect method of determination using nitroblue-tetrazolium, being the most common and efficient method. The principle of the method is based on the use of WST tetrazolium salt, highly water soluble, which produces a colored substance by reducing the superoxide anion. The rate of molecular oxygen reduction is linearly correlated with xanthine oxidase activity and is inhibited by SOD. Since the absorbance at $450 \mathrm{~nm}$ is proportional to the concentration of the superoxide anion, the SOD activity can be quantified by measuring the reaction medium colour intensity at $450 \mathrm{~nm}$ and expressed as inhibition rate $(\%)$. The specific activity of SOD was then reported considering the total soluble proteins content (determined using Bradford assay technique). The SOD activity was therefore expressed as enzyme units/ milligram (U/mg) (CIOBICA \& al, 2012 [20]).

4.2. Glutathione peroxidase (GPx) activity determination

To determine the enzymatic activity of GPx, the "Glutathione Peroxidase Cellular Activity Assay Kit" (Sigma-Aldrich, United States of America) was used. The kit uses an indirect measurement method based on the oxidation of glutathione in oxidized glutathione, a catalysed reaction of the glutathione peroxidase enzyme and coupled with the reduced glutathione recycle, the glutathione reductase-catalyzed reaction. Throughout this series of reactions, the concentration changes of the NADPH enzyme cofactor, the reduced form, are measured. Decrease in absorbance measured at $340 \mathrm{~nm}$ during NADPH oxidation to NADP + is directly proportional to GPx activity, since the enzyme is the modulating torque of the reaction. The reaction is carried out at $25^{\circ} \mathrm{C}$ and $\mathrm{pH} 8.0$ and is initiated by the addition of an organic peroxide, tert-butyl hydroperoxide (t-Bu-OH) to the reaction medium. Preparation of reagents Glutathione Peroxidase Assay Buffer, NADPH Assay Reagent, tert-butyl hydroperoxide $30 \mathrm{mM}$ were performed according to the manufacturer instructions. The results were reported to the total protein samples content, and GPX activity was expressed as GPX enzyme units/ mg (U/mg) (CIOBICA \& al, 2012 [20]).

\subsection{Malondialdehyde concentration determination}

Malondialdehyde (MDA) concentrations were determined using thiobarbituric acid reactive substances (TBARs) assay method, previously described (CIOBICA \& 
al, 2011 [21]). A $0.1 \mathrm{ml}$ brain and colon extracts samples were pipetted into a centrifuge tube. $1 \mathrm{ml}$ of $50 \%$ trichloroacetic acid solution and $1.1 \mathrm{ml}$ of thiobarbituric acid were added. The tubes covered with a small glass funnel were kept for 20 minutes in a boiling water bath. After cooling the tubes under the jet of water, they were centrifuged for 10 minutes at 3,000 rpm and spectrophotometrically read $(\lambda=532 \mathrm{~nm})$ versus control consisting of $0.1 \mathrm{ml}$ of distilled water, $1 \mathrm{ml}$ of $50 \%$ trichloroacetic acid and 1,1 ml of thiobarbituric acid (Beckman Coulter, Canada). The signal was read against an MDA standard curve and the results were expressed as nmol/mg protein.

\section{Statistical analysis}

The raw data was statistically analysed using one-way analysis of variance (ANOVA) using a statistical analysis software (Minitab 17). F values for which $p<0.05$ were regarded as statistically significant. Post hoc analyses were performed using Tukey's honestly significant difference test in order to compare groups.

\section{Results and Discussion}

The fatty acids profile of Camelina sativa, Madalina variety cold pressed oil has is presented in Table 1 and the main components are similar with the composition of
Camelina oil of different varieties earlier published (DOMIL \& PîRVUlescu, 2015 [11], POPA \& al, 2019 [12], AHMED \& al, 2019 [22], KANCLERZ \& al, 2019 [23], KICZOROWSKA \& al, 2019 [24, KURASIAK-POPOWSKA \& al, 2019 [25], TEJERA \& al, 2016 [26], TERPINC \& al, 2012 [27]). The chromatographic analyses revealed that the oil contained the highest amount of polyunsaturated fatty acids (PUFA: $54.84 \%$ ), followed by monounsaturated fatty acids (MUFA $35.87 \%$ ) and a low content of saturated fatty acids (SFA: 9.29\%). The main components determined in our sample were: $37.77 \% \alpha$-linolenic acid $(\mathrm{C} 18: 3, \omega-3), 17.07 \%$ linoleic acid (C18:2, $\omega-6), 16.88 \%$ cis-11-eicosenoic acid (C20:1, $\omega-9), 14.05 \%$ oleic acid (C18:1, $\omega-9), 5.52 \%$ palmitic acid (C16:0), 4.03\% erucic acid (C22:1, $\omega-9)$, $2.11 \%$ stearic acid (C18:0), 1.36\% arachidic acid (C20:0). The components presented in concentration smaller than 1\% were: cis-13-eicosenoic acid (C20:1, $\omega-9)$, behenic acid (C22:0), myristic acid (C14:0), palmitoleic acid (C16:1, $\omega-7)$. The fatty acid profile and the value of the ratio $\omega-6$ : $\omega-3(0.45)$ obtained in our present study is very similar with that found by Erkkila et al (ERKKILA \& al, 2019 [28]). The values of the ratio $\omega-6: \omega-3$ was determined to be found in the range $0.42-0.58$, and this is dependent on the climate conditions, quality of land, (POPA \& al, 2019 [12]) presence of the heavy metals (PARK \& al, 2015 [29]), etc.

Table 1. Profile of fatty acids in Camelina oil determined in the present study and in some published research articles

\begin{tabular}{|c|c|c|c|c|c|c|}
\hline \multirow[b]{2}{*}{ Fatty Acid, Omega-n } & \multicolumn{6}{|c|}{ Percentage of Fatty Acids (\%) } \\
\hline & $\begin{array}{l}\text { Present study, } \\
\text { Madalina variety, } \\
\text { 2017, Romania }\end{array}$ & $\begin{array}{c}\text { Madalina } \\
\text { variety, 2018, } \\
\text { Romania } \\
\text { (POPA \& al, } \\
2019 \text { [12]) }\end{array}$ & $\begin{array}{l}\text { Banat region, } \\
\text { Romania } \\
\text { (DOMIL \& } \\
\text { PÎRVULESCU, } \\
2015 \text { [11]) }\end{array}$ & $\begin{array}{c}\text { Poland } \\
\text { (KANCLERZ } \\
\& \text { al, 2019 } \\
[23])\end{array}$ & $\begin{array}{c}\text { UK } \\
\text { (O’DWYER } \\
\& \text { al, 2013 } \\
[30])\end{array}$ & $\begin{array}{c}\text { Finland } \\
\text { (ERKKILA } \\
\& \text { al, 2019 } \\
[28])\end{array}$ \\
\hline Myristic acid (C14:0) & $0.08 \pm 0.03$ & 0.037 & ND & ND & LL & 0.1 \\
\hline Palmitoleic acid $(\mathrm{C} 16: 1, \omega-7)$ & $0.04 \pm 0.02$ & 0.070 & ND & ND & LL & 0.1 \\
\hline Palmitic acid (C16:0) & $5.52 \pm 0.07$ & 4.240 & 5.17 & 5.23 & 5.61 & 5.7 \\
\hline Linoleic acid $(\mathrm{C} 18: 2, \omega-6)$ & $17.07 \pm 0.31$ & 15.81 & 17.32 & 18.07 & 17.95 & 16.4 \\
\hline$\alpha$-Linolenic acid $(\mathrm{C} 18: 3, \omega-3)$ & $37.77 \pm 0.51$ & 27.05 & 30.46 & 34.73 & 33.8 & 38.4 \\
\hline Oleic acid $(\mathrm{C} 18: 1, \omega-9)$ & $14.05 \pm 0.57$ & 10.96 & 22.06 & 15.58 & 16.37 & 13.2 \\
\hline Stearic acid (C18:0) & $2.11 \pm 0.05$ & 1.86 & 3.03 & 2.33 & 2.49 & 2.5 \\
\hline cis-13-Eicosenoic acid (C20:1, $\omega-9)$ & $0.87 \pm 0.04$ & 1.52 & ND & ND & ND & ND \\
\hline cis-11-Eicosenoic acid (C20:1, $\omega-9)$ & $16.88 \pm 0.30$ & 14.04 & 17.16 & 14.31 & 14.24 & 14.7 \\
\hline Arachidic acid (C20:0) & $1.36 \pm 0.10$ & ND & 1.37 & ND & LL & 1.5 \\
\hline Erucic acid (C22:1, $\omega-9)$ & $4.03 \pm 0.06$ & ND & 1.75 & 3.12 & LL & 3.4 \\
\hline Behenic acid (C22:0) & $0.23 \pm 0.03$ & 0.28 & ND & ND & LL & 0.3 \\
\hline Nervonic acid $(\mathrm{C} 24: 1, \omega-9)$ & ND & ND & ND & 1.21 & LL & 0.6 \\
\hline SFA & 9.29 & 6.42 & 9.84 & 7.56 & 11.78 & 10.2 \\
\hline MUFA & 35.87 & 26.59 & 40.97 & 34.22 & 31.97 & 32.7 \\
\hline PUFA & 54.84 & 42.86 & 47.78 & 58.8 & 55.38 & 57.1 \\
\hline$\omega-6: \omega-3$ & 0.45 & 0.58 & 0.56 & 0.52 & 0.56 & 0.42 \\
\hline
\end{tabular}

ND, not detected, LL: low levels (not show)

In this report we tested the effects of Camelina sativa pressed oil in a zymosan-induced model of IBS. In fact, the connections between the physiological manifestations in IBS and its depressive-like or anxyolitic-like manifestations was previously suggested (COJOCARIU \& al, 2019 [3], BALMUS \& al, 2019 [31]) and we are showing here some facilitating effects of the Camelina sativa pressed oil in this context, both on the behavioral and oxidative stress-related actions.

Thus, regarding the memory, as tested in the Y maze, we could see in Figure 1 a significant improvement $(\mathrm{p}<0.05)$ in the short-term immediate spatial memory processes, as demonstrated by the increase in the spontaneous alternation percentage in IBS+ Camelina oil group, when compared to IBS group alone. 


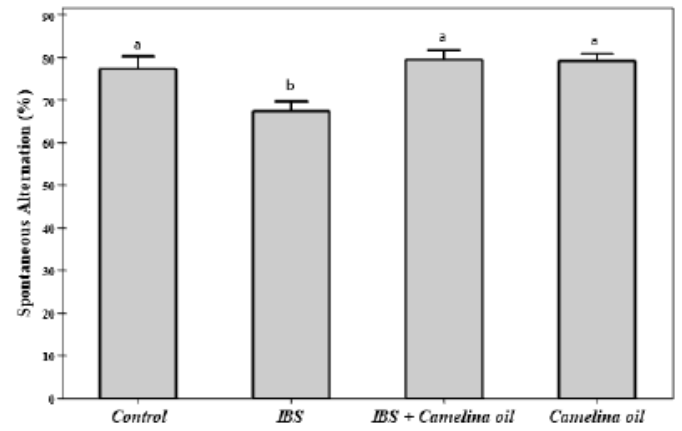

Figure 1. The effects of Camelina oil administration in a mice model of IBS on short term memory observed in Y Test.

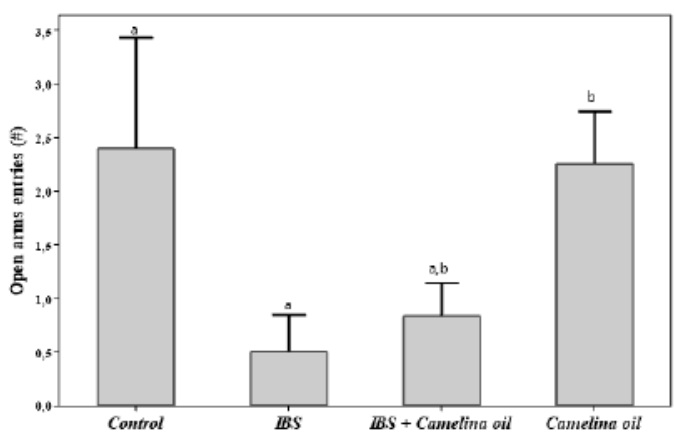

(a)

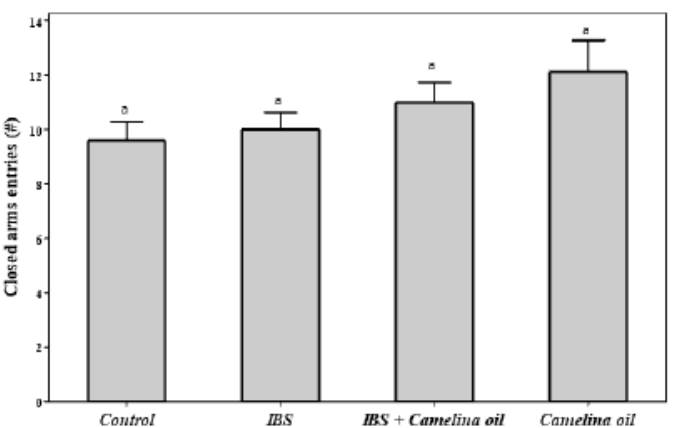

(c)

Figure 2. The effects of Camelina oil administration in a mice model of IBS on anxious behaviour observed in Elevated Plus maze: a. open arms time; b. open arms entries; c. closed arms entries; d. grooming behaviour durations. The results are expressed as means \pm S.E.M. The columns that do not share a letter are significantly different (a,b - Tukey HSD test).

In addition, in regards to the depressive-like behaviour, there are significant decreases $(\mathrm{p}<0,05)$ in the floating time in the IBS+ Camelina oil group, when compared to IBS

(a)

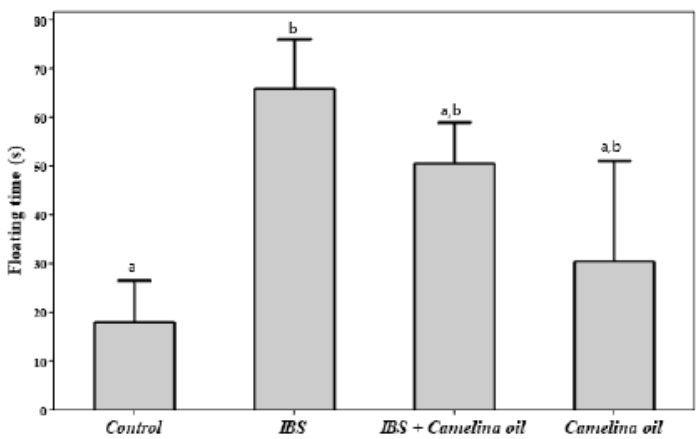

Figure 3. The effects of Camelina oil administration in a mice model of IBS on anxious behaviour observed in Forced Swim Test: a. struggle behaviour duration; b. floating behaviour duration. The results are expressed as means \pm S.E.M. The columns that do not share a letter are significantly different ( $a, b$ - Tukey HSD test).

group alone (Figure 3a), as well as in the struggle time, as it can be seen in the Figure $3 \mathrm{~b}$ below:

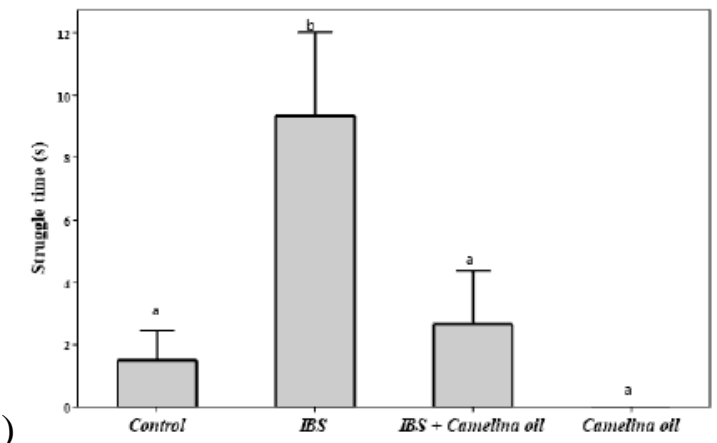

The results are expressed as means \pm S.E.M. The columns that do not share a letter are significantly different ( $a, b$ - Tukey HSD test).

The same happens when we analyzed the anxietyrelated processes, as studied in the specific elevated plus maze task, where we observed a significant $(\mathrm{p}<0,05)$ increase in the number of open arms entries in the IBS + Camelina oil group, as compared IBS alone group (Figure 2a). Also, there is a significant increase in the time spent in the open arms in the Camelina-treated group vs. IBS alone (Figure 2b).
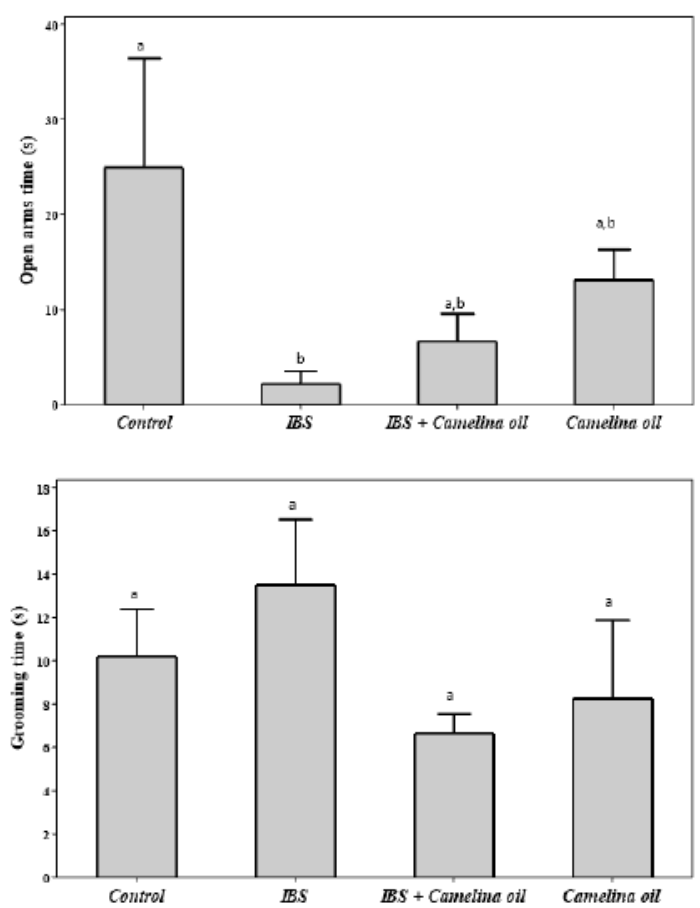
Also, there were significant ameliorations of the social manifestations, as it can be seen below in the
IBS + Camelina oil group, as compared only with the rats which had the experimental model of IBS (Figure 4).
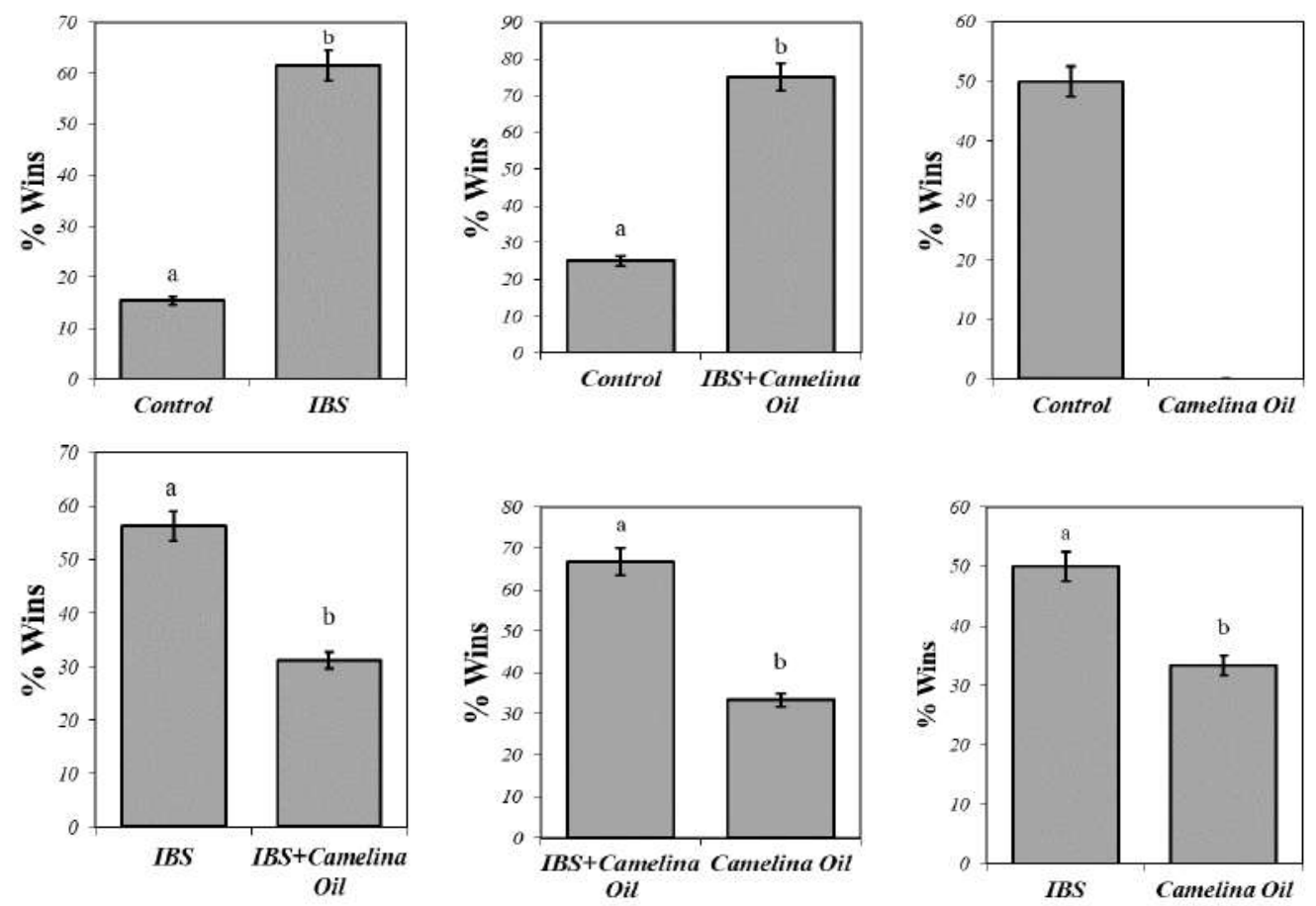

Figure 4. The effects of Camelina oil administration in a mice model of IBS on social domination and aggressive behaviour observed in Social Dominance Test. The results are expressed as means \pm S.E.M. The columns that do not share a letter are significantly different (a,b - Tukey HSD test).

Moreover, when it comes to the effects of this extract on the oxidative stress status, as it can be seen in the Figures $5,6,7$, and 8 , our results are suggesting an antioxidant effect. Significant differences between the studied groups were observed regarding the SOD activity (Overall

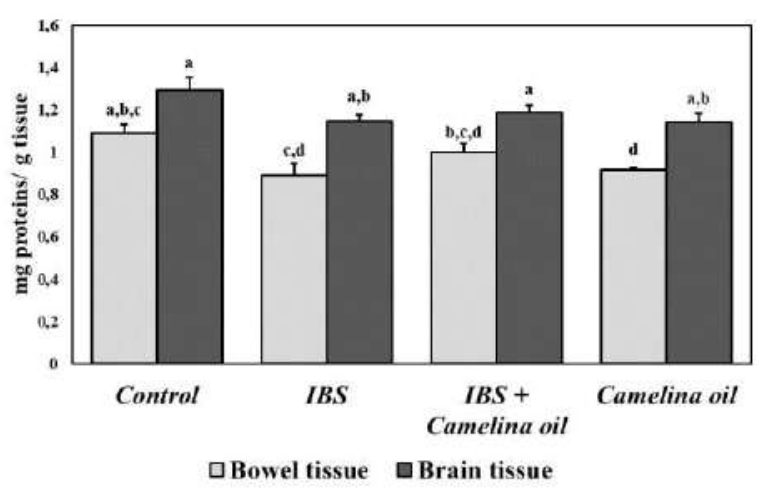

Figure 5. The effects of Camelina oil administration in a mice model of IBS on the total soluble proteins levels evaluated from brain and bowel tissues. The results are expressed as means \pm S.E.M. The columns that do not share a letter are significantly different (a,b,c,d - Tukey HSD test).
ANOVA $p_{\text {bowel }}<0.01$ ) (Figure 6) and MDA levels (Overall ANOVA $\mathrm{p}_{\text {bowel }}<0.01, \mathrm{p}_{\text {brain }}<0.01$ ) (Figure 8 ) in both brain and bowel tissues extracts. Relevant, but not statistically significant overall changes were observed for GPx activity (Figure 7) and total soluble proteins (Figure 5).

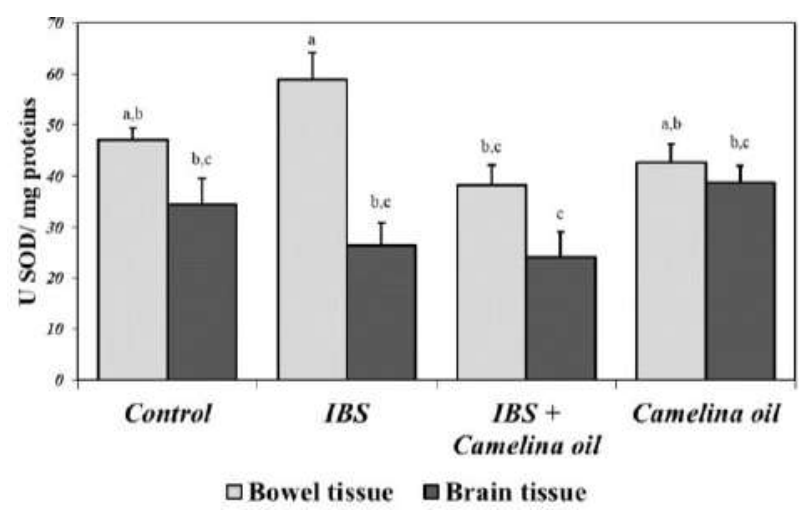

Figure 6. The effects of Camelina oil administration in a mice model of IBS on the SOD specific activity evaluated from brain and bowel tissues. The results are expressed as means \pm S.E.M. The columns that do not share a letter are significantly different (a,b,c - Tukey HSD test). 


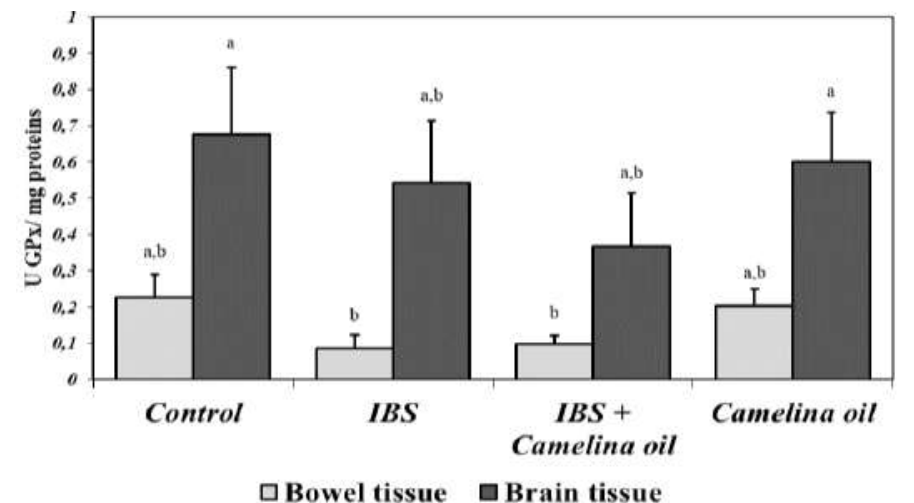

Figure 7. The effects of Camelina oil administration in a mice model of IBS on the GPx specific activity evaluated from brain and bowel tissues. The results are expressed as means \pm S.E.M The columns that do not share a letter are significantly different (a,b - Tukey HSD test).

Thus, all these results are suggesting some beneficial effects for the Camelina sativa Madalina variety oil used in this study on behavioural (memory, anxiety, depression and social-related) manifestations and oxidative stress parameters in a zymosan-mice model of irritable bowel syndrome, even though some studies regarding cognitive deficiencies in IBS patients turned out to be contradictory, some authors considering the data as being not entirely clear on this matter (BERRILL \& al, 2013 [32], FARUP \& HESTAD, 2015 [33]). This could be relevant for the connections between the physiological manifestations in IBS and its depressive-like or anxiolytic-like manifestations, in accordance with specialized literature in what concerns the human studies (FARUP \& HESTAD 2015 [33], CRYAN \& al, 2002 [34]), like we previously discussed and published (COJOCARIU \& al, 2019 [3], LEFTER \& al, 2018 [4], BALMUS \& al, 2019 [31]), since we are showing here some facilitating effects of this specific Camelina oil in this context, on both the behavioral and oxidative stress-related actions.

Also, this could be connected with the fact that this oil was previously suggested to have laxative effects (KANCLERZ \& al, 2019 [23], FRASER \& al, 2017 [35]), as this correlates for example with increased MDA concentration in the oil group (e.g. as in increased membrane permeability), when compared for example with the controls (Figure 8). Regarding Camelina sativa, this specific plant is known for being a rich source of omega- 3 fatty acids, and one possible mechanism regarding its protective effect could be linked to decreased inflammation, especially when recent studies revealed beneficial effect in immunoregulatory function, with a decrease in mRNA expression levels of IFN $\gamma$ after a 12-week diet enriched with Camelina sativa oil. Moreover, there are documented benefits in terms of cardiovascular health, given the reduced levels of ICAM1 expression induced by a lean fish diet, when compared to a fatty fish or a control diet (DE MELLO \& al, 2019 [36]).

Recent studies indicated that polyphenols are implicated in reversing oxidative stress, alleviating some cognitive and mood disorders (SAJILATA \& al, 2008 [37],

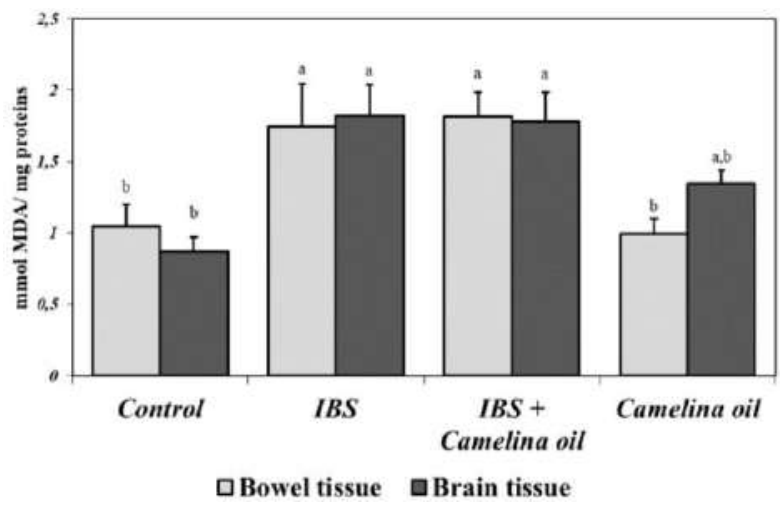

Figure 8. The effects of Camelina oil administration in a mice model of IBS on the malondialdehyde levels evaluated from brain and bowel tissues. The results are expressed as means \pm S.E.M. The columns that do not share a letter are significantly different (a,b,c,d - Tukey HSD test).
SANMUKHANI \& al, 2014 [38]). Even though Camelina sativa oil did not cause obvious changes in oxidative stress status in subjects with impaired glucose metabolism (ERKKILA \& al, 2019 [28]), this plant is considered to be more stable toward oxidation, with an antioxidant activity high enough to be considered a potential source of bioactive antimicrobial preservative used in pharmaceutical applications (KUMAR \& al, 2015 [39]).

Oxidation stability is also given by the increased level of gamma-tocopherol, chlorogenic acid, which slows the release of glucose into the bloodstream (ABRAMOVIC \& al, 2007 [40], HRASTAR \& al, 2011 [41]), and it is known for increasing serum concentrations of eicosapentaenoic acid (EPA) and docosahexanoic acid (DHA) (CUTULI, 2017 [42]), with beneficial effects on cardiovascular disease (MOZAFFARIAN, 2008 [43]), autoimmune (CALDER, 2006 [44]), mental disorders (MCCANN \& AMES, 2005 [45]) and fetal development (TEJERA \& al, 2016 [26]). Even though two strains of Camelina sativa crop have been genetically modified to produce oil containing EPA or DHA, to compensate for the low synthesis capacity in humans, these seed oils could be a valid replacement of fish oil to provide a sustainable solution for EPA and DHA demands in human consumption (WEST \& al, 2019 [46]).

Also, there is an obvious link between PUFAs consumption and modulatory effects on expression and secretion of cytokines and chemokines (IL-1, IL-6 and TNF alfa) in both humans and pigs (TARANU \& al, 2014 [47]), while there is a stimulatory or an inhibitory effect of $\omega-3$ fatty acids on the pro-inflammatory cytokines in mice (CALDER, 1996 [48]). Camelina sativa oil-cakes consumption in pigs indicated an obvious modulation between Th1/ Th2 cytokine balance, and induction or suppression on one of these two cytokines, could be easily be used in nutritional treatment strategies and immunological approaches (TARANU \& al, 2014 [47]). In addition, the aminoacid of the Camelina oil content could also play a role in this context (BĂTRÎNA \& al, 2020 [8]). 


\section{Conclusions}

Our data presented here is suggesting some beneficial effects of the Camelina oil on behavioural (short term memory - tested in the Y maze task, anxiety - tested in the elevated plus maze, depression - as observed in the forced swimming test and social behaviour observed in socialdominance test) manifestations and oxidative stress parameters (the two main antioxidant enzymes determined here: superoxide dismutase and glutathione peroxidase, as well as a reduction in the lipid peroxidation marker malondialdehyde) in a zymosan-induced mice model of irritable bowel syndrome.

\section{Acknowledgments}

$\mathrm{AC}$ and IMB are supported by a research grant for Young Teams funded by UEFISCDI Romania, no. PNIIIP1-1.1-TE-2016-1210, contract no. 58 from 02/05/2018, called "Complex study regarding the interactions between oxidative stress, inflammation and neurological manifestations in the pathophysiology of irritable bowel syndrome (animal models and human patients)." CRO was funded by the European Social Fund, through Operational Programme Human Capital 2014-2020, project number POCU/380/ 6/13/123623, project title "PhD Students and Postdoctoral Researchers Prepared for the Labour Market!" Funding for some of the equipment used in the study has been provided by the European Commission and the Romanian Government (project POSCCE 621/2014).

\section{References}

1. Longstreth GF, Thompson WG, Chey WD, Houghton LA, Mearin F, SpILler RC. Functional bowel disorders. Gastroenterology, 130: 1480 (2006).

2. MAYER EA. Gut feelings: the emerging biology of gut-brain communication. Nature Reviews Neuroscience, 12: 453 (2011).

3. Cojocariu R, Ciobica A, Balmus im, Guenne S, Trifan A, Stanciu C et al. Antioxidant Capacity and Behavioral Relevance of a Polyphenolic Extract of Chrysanthellum americanum in a Rat Model of Irritable Bowel Syndrome. Oxidative Medicine and Cellular Longevity, 2019: (2019).

4. Lefter R, Ciobica A, Guenne S, Compaore M, Kiendrebeogo M, Stanciu $\mathrm{C}$ et al. Complex Neurobehavioral Testing of a Rat Model of the Irritable Bowel Syndrome. Neurophysiology, 50: 266 (2018).

5. Achitei D, Ciobica A, Balan G, Gologan E, Stanciu C, Stefanescu G. Different Profile of Peripheral Antioxidant Enzymes and Lipid Peroxidation in Active and Non-active Inflammatory Bowel Disease Patients. Digestive Diseases and Sciences, 58: 1244 (2013).

6. Ilie OD, Ciobica A, MCKenna J, Doroftei B, MAVROUDIS I. Minireview on the Relations between Gut Microflora and Parkinson's Disease: Further Biochemical (Oxidative Stress), Inflammatory, and Neurological Particularities. Oxidative Medicine and Cellular Longevity, 2020: 1 (2020).
7. Chaudhari N, Talwar P, Parimisetty A, D'Hellencourt CL, RAVANAN P. A molecular web: endoplasmic reticulum stress, inflammation, and oxidative stress. Frontiers in Cellular Neuroscience, 8: (2014).

8. BĂtrîna ȘL, JuRCOANE Ș, PoPESCU I, MARIN F, IMBreA IM, CRISTA F et al. Camelina sativa: A study on amino acid content. Rom Biotechnol Lett, 25: 1136 (2020).

9. BASNAYAKE C. Treatment of irritable bowel syndrome. Australian Prescriber, 41: 145 (2018).

10. Ford AC, Quigley EMM, LACY BE, LEMbo AJ, SAITO YA, SCHILLER LR et al. Effect of Antidepressants and Psychological Therapies, Including Hypnotherapy, in Irritable Bowel Syndrome: Systematic Review and MetaAnalysis. American Journal of Gastroenterology, 109: 1350 (2014).

11. Domil G, Pîrvulescu LP, Iuliana M. The Study of Camelina Oil Characteristics. Research Journal of Agricultural Science, 47: 55 (2015).

12. Popa Al, Drumea V, Nita RA, Florea MA, Olariu L, JURCOANE $S$ et al. A physico-chemical characterization of oil from Camelina sativa seeds grown in Romania. Romanian Biotechnological Letters, 24: 776 (2019).

13. Craciun LM, Dumitriu BG, Olariu L, Jurcoane S, CRISTEA S, ADIL A et al. Regenerative and scare healing potential of active compounds from Camelina sativa oil and grape pomace. Romanian Biotechnological Letters, 24: 1075 (2019).

14. PILlEMER L, ECKER EE. Anticomplementary Factor in Fresh Yeast The Journal of Biological Chemistry, 137: 139 (1941).

15. UNDERHILL DM. Macrophage recognition of zymosan particles. Journal of Endotoxin Research, 9: 176 (2003).

16. Taghavi M, Mortaz E, Khosravi A, Vahedi G, FOLKERTS G, VARAHRAM M et al. Zymosan attenuates melanoma growth progression, increases splenocyte proliferation and induces TLR-2/4 and TNF-alpha expression in mice. Journal of Inflammation - London, 15: (2018).

17. Copolovici D, Bungau S, Boscencu R, Tit DM, Copolovici L. The Fatty Acids Composition and Antioxidant Activity of Walnut Cold Press Oil. Revista de Chimie, 68: 507 (2017).

18. Csakvari AC, Lupitu A, Bungau S, Gitea MA, Gitea D, TIT DM et al. Fatty Acids Profile and Antioxidant Activity of Almond Oils Obtained from Six Romanian Varieties. Farmacia, 67: 882 (2019).

19. RABA DN, Chambre DR, COPOLOVICI DM, Moldovan $\mathrm{C}$, COPOlOVICI LO. The influence of high-temperature heating on composition and thermo-oxidative stability of the oil extracted from Arabica coffee beans. Plos One, 13: (2018).

20. Ciobica A, Olteanu Z, Padurariu M, Hritcu L. The effects of pergolide on memory and oxidative stress in a rat model of Parkinson's disease. Journal of Physiology and Biochemistry, 68: 59 (2012).

21. Ciobica A, Hritcu L, Nastasa V, Padurariu M, BILD W. INHIBITION OF CENTRAL ANGIOTENSIN CONVERTING ENZYME EXERTS ANXIOLYTIC EFFECTS BY DECREASING BRAIN OXIDATIVE STRESS. Journal of Medical Biochemistry, 30: 109 (2011).

22. Ahmed Z, Waraich EA, Qi ZM, Gui DW, Shreef M, IQBAL $\mathrm{H}$ et al. Physio-Biochemical and Yield Responses of Two Contrasting Camelina sativa Breeding Lines under 
Drought Stress. International Journal of Agriculture and Biology, 22: 1187 (2019).

23. Kanclerz A, Drozinska E, KureK MA. Microencapsulation of Camelina sativa Oil Using Selected Soluble Fractions of Dietary Fiber as the Wall Material. Foods, 8: (2019).

24. Kiczorowska B, SAMOLInSKa W, ANDREJKo D, KICZOROWSKI P, ANTOSZKIEWICZ Z, ZAJAC $\mathrm{M}$ et al. Comparative analysis of selected bioactive components (fatty acids, tocopherols, xanthophyll, lycopene, phenols) and basic nutrients in raw and thermally processed camelina, sunflower, and flax seeds (Camelina sativa L. Crantz, Helianthus L., and Linum L.). Journal of Food Science and Technology-Mysore, 56: 4296 (2019).

25. KURASIAK-POPOWSKA D, RYNSKA B, STUPERSzABLEWSKA K. Analysis of Distribution of Selected Bioactive Compounds in Camelina sativa from Seeds to Pomace and Oil. Agronomy-Basel, 9: (2019).

26. Tejera N, Vauzour D, Betancor MB, Sayanova O, UsHer S, COCHARD $M$ et al. A Transgenic Camelina sativa Seed Oil Effectively Replaces Fish Oil as a Dietary Source of Eicosapentaenoic Acid in Mice. Journal of Nutrition, 146: 227 (2016).

27. Terpinc P, Polak T, Makuc D, Ulrih NP, AbraMOVIC $H$. The occurrence and characterisation of phenolic compounds in Camelina sativa seed, cake and oil. Food Chemistry, 131: 580 (2012).

28. ERKKILA AT, LEE JCY, LANKINEN M, MANNINEN S, Leung HH, OGer C et al. Camelina sativa Oil, Fatty Fish, and Lean Fish Do Not Markedly Affect Urinary Prostanoids in Subjects with Impaired Glucose Metabolism. Lipids, 54: 453 (2019).

29. Park W, Feng Y, Kim H, Suh MC, Ahn SJ. Changes in fatty acid content and composition between wild type and CsHMA3 overexpressing Camelina sativa under heavymetal stress. Plant Cell Reports, 34: 1489 (2015).

30. O'DwYer SP, O'BeIRNE D, Ni' EIDHIN D, O'KenNEDY BT. Effects of emulsification and microencapsulation on the oxidative stability of camelina and sunflower oils. Journal of Microencapsulation, 30: 451 (2013).

31. Balmus I-M, Lefter R, Ciobica A, CojocAru S, Guenne S, Timofte6 D et al. Preliminary Biochemical Description of Brain Oxidative Stress Status in Irritable Bowel Syndrome Contention-Stress Rat Model. MedicinaLithuania, 55: 776 (2019).

32. Berrill JW, Gallacher J, Hood K, Green JT, MATTHEWS SB, CAMPBELl AK et al. An observational study of cognitive function in patients with irritable bowel syndrome and inflammatory bowel disease. Neurogastroenterology and Motility, 25: 918 (2013).

33. Farup PG, Hestad K. Cognitive Functions and Depression in Patients with Irritable Bowel Syndrome. Gastroenterology Research and Practice: (2015).

34. CRYAN JF, MARKOU A, LUCKI I. Assessing antidepressant activity in rodents: recent developments and future needs. Trends in Pharmacological Sciences, 23: 238 (2002).

35. Fraser JM, Collins SA, Chen Z, TibBetts SM, LALl SP, ANDERSON DM. Effects of dietary Camelina sativa products on digestible nutrient compositions for rainbow trout (Oncorhynchus mykiss). Aquaculture Nutrition, 23: 973 (2017)

36. DE Mello VD, Dahlman I, Lankinen M, KuRl S, PITKANEN L, LAAKSONEN DE et al. The effect of different sources of fish and camelina sativa oil on immune cell and adipose tissue mRNA expression in subjects with abnormal fasting glucose metabolism: a randomized controlled trial. Nutrition \& Diabetes, 9: (2019).

37. SAJILATA MG, BAJAJ PR, Singhal RS. Tea polyphenols as nutraceuticals. Comprehensive Reviews in Food Science and Food Safety, 7: 229 (2008).

38. Sanmukhani J, Satodia V, Trivedi J, Patel T, Tiwari D, PANCHAL B et al. Efficacy and Safety of Curcumin in Major Depressive Disorder: A Randomized Controlled Trial. Phytotherapy Research, 28: 579 (2014).

39. KuMAR K, GuPTA SM, ARYA MC, NASIM M. In Vitro Antimicrobial and Antioxidant Activity of Camelina Seed Extracts as Potential Source of Bioactive Compounds. Proc Natl Acad Sci, India, Sect B Biol Sci 87: 521 (2015).

40. Abramovic H, Butinar B, Nikolic V. Changes occurring in phenolic content, tocopherol composition and oxidative stability of Camelina sativa oil during storage. Food Chemistry, 104: 903 (2007).

41. Hrastar R, CheOng LZ, Xu XB, Jacobsen C, Nielsen NS, MILlER RL et al. Deodorization optimization of Camelina sativa oil: Oxidative and sensory studies. European Journal of Lipid Science and Technology, 113: 513 (2011).

42. Cutuli D. Functional and Structural Benefits Induced by Omega-3 Polyunsaturated Fatty Acids During Aging. Current Neuropharmacology, 15: 534 (2017).

43. MOZAFFARIAN D. Fish and n-3 fatty acids for the prevention of fatal coronary heart disease and sudden cardiac death. American Journal of Clinical Nutrition, 87: 1991S (2008).

44. CALDER PC. n-3 polyunsaturated fatty acids, inflammation, and inflammatory diseases. American Journal of Clinical Nutrition, 83: 1505S (2006).

45. MCCANN JC, AMES BN. Is docosahexaenoic acid, an n-3 long-chain polyunsaturated fatty acid, required for development of normal brain function? An overview of evidence from cognitive and behavioral tests in humans and animals. American Journal of Clinical Nutrition, 82: 281 (2005).

46. West AL, Miles EA, Lillycrop KA, Han LH, SAYANOVA O, NAPIER JA et al. Postprandial incorporation of EPA and DHA from transgenic Camelina sativa oil into blood lipids is equivalent to that from fish oil in healthy humans. British Journal of Nutrition, 121: 1235 (2019).

47. Taranu I, Gras M, Pistol GC, Motiu M, Marin DE, LEFTER N et al. Omega-3 PUFA Rich Camelina Oil ByProducts Improve the Systemic Metabolism and Spleen Cell Functions in Fattening Pigs. Plos One, 9: (2014).

48. CALDER PC. Sir David Cuthbertson medal lecture immunomodulatory and anti-inflammatory effects of n-3 polyunsaturated fatty acids. Proceedings of the Nutrition Society, 55: 737 (1996). 